\title{
AS MODAS E OS MODOS: A MULHER REPRESENTADA NAS REVISTAS FEMININAS
}

\author{
Bruna Batista Ferreira ${ }^{1}$
}

\begin{abstract}
Resumo: As revistas femininas foram, entre as décadas de 1950 a 1970, uma importante fonte de referência para as mulheres da classe média brasileira. Nesses periódicos circulavam ideias sobre aparência e comportamento, em outras palavras, sobre as modas e os modos ditos femininos. Lições sobre beleza, decoro, casamento, maternidade e culinária estampavam as páginas, bem como as imagens de mulheres consideradas belas e os anúncios publicitários embutidos de artigos para a vida doméstica feminina. Todavia, a vida das mulheres nesse período mudava com a já adquirida inserção nos empregos fora do lar, os avanços técnicocientíficos e educacionais. As revistas precisavam comportar o mesmo dinamismo, embora tivessem dificuldades em identificar apenas um tipo de mulher como público-alvo. Para manterem-se interessantes para esses públicos eram necessárias concepções mais generalistas. Num cenário no qual falar de feminino precisou também abarcar o feminismo, as revistas amparavam os enlaces culturais, entre mudanças e permanências, de uma época.
\end{abstract}

Palavras-chave: Revistas femininas; modos; modas; mulher; representação.

Abstract: Women's magazines were, between the 1950s and 1970s, an important reference source for women in the Brazilian middle class. In these periodicals ideas about appearance and behavior circulated, in other words, about the so-called feminine fashions and manners. Lessons on beauty, decorum, marriage, motherhood and cooking stamped the pages, as well as images of women considered beautiful and the advertisements embedded in articles for female domestic life. However, women's lives in that period changed with the already acquired insertion in jobs outside the home, the technical-scientific and educational advances. Magazines needed to be as dynamic, although they had difficulties in identifying only one type of woman as a target audience. To remain interesting for these audiences, more generalist conceptions were needed. In a scenario in which talking about feminine also needed to embrace feminism, magazines supported the cultural links, between changes and permanences, of an era.

Keywords: Women's magazines; modes; fashions; woman; representation.

Resumen: Las revistas para mujeres fueron, entre los años cincuenta y setenta, una importante fuente de referencia para las mujeres de la clase media brasileña. En estos periódicos circulaban ideas sobre la apariencia y el comportamiento, en otras palabras, sobre las llamadas modas y modales femeninas. Lecciones sobre belleza, decoro, matrimonio, maternidad y cocina estamparon las páginas, así como imágenes de mujeres consideradas hermosas y los anuncios incrustados en artículos para la vida doméstica femenina. Sin embargo, la vida de las mujeres en ese período cambió con la inserción ya adquirida en trabajos fuera del hogar, los avances técnicos, científicos y educativos. Las revistas debían ser

\footnotetext{
${ }^{1}$ Mestre em Patrimônio Cultural, Paisagens e Cidadania pela Universidade Federal de Viçosa (UFV). Doutoranda do Programa de Pós-Graduação em História pela Universidade Federal Fluminense. E-mail: brunabatistaferreira@id.uff.br. ORCID: https://orcid.org/0000-0002-7337-0534. Este artigo é fruto das pesquisas realizadas durante a Dissertação de Mestrado.
} 
tan dinámicas, aunque tenían dificultades para identificar a un solo tipo de mujer como público objetivo. Para seguir siendo interesante para estas audiencias, se necesitaban concepciones más generalistas. En un escenario en el que hablar sobre lo femenino también necesitaba abrazar el feminismo, las revistas apoyaron los vínculos culturales, entre cambios y permanencias, de una época.

Palabras-clave: revistas de mujeres; modos; modas; mujer; representación.

\section{As Revistas Femininas}

Entre as décadas de 1940 e 1960 as revistas femininas foram "uma importante fonte de informação e referência para as mulheres, principalmente leitoras de classe média" (BASSANEZI, 1997)2 ${ }^{2}$ Adentrando os espaços domésticos, elas atuavam como "guias de ação, conselheiras persuasivas, companheiras de lazer ou alienação" (BASSANEZI, 1997, p. 112.). Com um discurso nem sempre homogêneo e linear, esses materiais participam da reprodução e da construção do ideal de felicidade conjugal. Serviam de espaço onde eram transmitidas normas e representações sociais. Até atinavam para novas possibilidades e formas de pensar as relações entre homem e mulher, desde que ficassem garantidas as "bases morais e valorativas e que as vendas e a publicidade não [saíssem] prejudicadas" (BASSANEZI, 1997, p. 145). O que prevalecia era a aceitação do "natural", do biológico, que servia inclusive como reafirmação da condição "feminina", da feminilidade:

Ser mãe, esposa e dona de casa era considerado o destino natural das mulheres. Na ideologia dos Anos Dourados, maternidade, casamento e dedicação ao lar faziam parte da essência feminina; sem história e sem possibilidades de contestação. A vocação prioritária para a maternidade e a vida doméstica seriam marcas da feminilidade, enquanto iniciativa, a participação no mercado de trabalho, a força e o espírito de aventura definiriam a masculinidade. A mulher que não seguisse seus caminhos estaria indo contra a natureza, não poderia ser realmente feliz ou fazer com que as outras pessoas fossem felizes (PINSKY, 2015, p. 609-610).

As expressões: "moça de família x moça leviana"; "boas moças x mal faladas"; "bom caminho x más influências"; "para casar x maçaneta"; faziam parte do vocabulário da época e das instruções contidas nas páginas dos periódicos. No conteúdo de $O$ Cruzeiro era dado, por exemplo, que o jeito do rapaz tratar uma moça dependeria muito de seu comportamento (PINSKY, 2015, p. 607-639). "Deflorar-se" antes do casamento era gravíssimo, não correspondia com a "boa moral". A noiva que não era mais virgem estava passiva de ter seu casamento anulado, no qual o recém-casado poderia alegar "induzimento a erro essencial", garantindo punições à moça deflorada por outro (PINSKY, 2015, p. 628).

\footnotetext{
${ }^{2}$ Segundo Carla Bassanezi, conclui-se a classe social das principais leitoras inferindo os "dados do IBOPE (pesquisa de opinião pública), das propagandas, dos textos das próprias revistas (que se afirmam como publicações de classe média), do conteúdo específico dos artigos e das cartas de leitores publicadas”.
} 
Não só os "modos", o comportamento, condiziam com a moça possuir ou não a "boa moral". As "modas", ou seja, a vestimenta e aparência eram fatores extremamente importantes, no que se refere a passar uma imagem virtuosa. Embelezar-se para o marido era obrigação de uma esposa boa que desejava manter seu casamento. As aventuras extraconjugais, tipicamente associadas à figura masculina, poderiam ser esquecidas se em casa o homem tivesse uma companheira perfeita e atraente. Perfeita, no sentido de não medir esforços para ver a felicidade do cônjuge. Seu dever não correspondia necessariamente em se comunicar com o marido, nem compartilhar experiências ou ideias, mas sim acompanhá-lo nas opiniões, reconhecer seus gostos e desejos, inspirando-o, confortando-o, animando-o (PINSKY, 2015, p. 628).

A moça dos anos 1950, no mais das vezes, deveria seguir uma lógica: preparar-se para a vida de esposa e mãe, estando sempre ao lado do marido e a par da vida dos filhos. A mídia propagandista e o comércio abarcavam essa procedência e utilizavam-se da vivência feminina para disseminar seus produtos "imprescindíveis" ao cotidiano. As aparições de enceradeiras, aspiradores de pó, alvejantes, além de maquiagens, produtos para cabelos e higiene nos anúncios publicitários evidenciavam as conotações atribuídas ao "ser mulher", ligado diretamente aos bens materiais do lar e aos cosméticos. Nesse panorama, de acordo com Raquel de Barros Pinto Miguel, vemos a possibilidade que os anúncios abriam para a análise dos papéis sociais destinados às mulheres das décadas de 1950 e 1960 (MIGUEL, 2008). Refletindo ainda sobre a possível participação das propagandas na constituição das subjetividades das mulheres e homens de uma geração e utilizando exemplares da revista Capricho, a autora considera que:

As mulheres exibidas em anúncios dos anos 50, e também do início dos anos 60 , retratavam o ideal da "moça prendada moderna", uma vez que deveriam estar atentas aos cuidados da casa, dos filhos, do marido devendo, ainda, manterem-se sempre belas. Para conseguirem cumprir todas essas tarefas, as mulheres contavam com importantes aliados: batedeira, máquina de lavar roupa, sabão em pó e enceradeira de um lado, e cremes contra rugas, sabonetes perfumados e poderosos dentifrícios de outro (MIGUEL, 2008, p. 4).

Concomitantemente ao ideal de "boa moça", "boa esposa" e "boa mãe" propagado nos jornais e revistas, outro grande veículo midiático, o cinema hollywoodiano, explodia e trazia beijos apaixonados entre jovens namorados. Musas emergiam e com elas novos comportamentos e ideais de beleza. Marylin Monroe tornava-se símbolo sexual. A exuberância e a ousadia sobreposta em seus filmes, apresentações musicais e aparições revelavam uma outra face do ser mulher e do ser "feminina". É nesse sentido que Pinsky 
afirma que não devemos esquecer as pessoas, que vivendo nos Anos Dourados, possuíam ideais diferenciados, ousados, corajosos, ansiando renovação ${ }^{3}$. Para a estudiosa foram estas pessoas que permitiram que estes anos tivessem também "outras tonalidades e cores" (PINSKY, 2015, p. 607-639). Assim, mesmo em meio às perspectivas comportamentais intrínsecas e associadas aos anos 1950 passaram, nas décadas subsequentes, a serem revisados e avaliados os papéis sociais das mulheres, por meio inclusive de reivindicações acerca dos códigos jurídicos, lutas contra a violência, opressão e discriminação.

\section{Cenário em revista}

As questões trabalhistas modificadas como a dinâmica industrial e o contexto das guerras do início do século XX conferiam, já nos anos 1950 novos ares à vivência feminina. As lutas por igualdade de direitos entre os gêneros tornavam-se pauta. Ao descrever a vida e a mulher dos Anos Dourados Carla Bassanezi Pinsky elucida que:

O Brasil dos anos 50 viveu um período de ascensão da classe média. Com o fim da Segunda Guerra Mundial, o país assistiu otimista e esperançoso ao crescimento urbano e à industrialização sem precedentes que conduziram ao aumento das possibilidades educacionais e profissionais para homens e mulheres. Democracia e participação eram ideias fortalecidas nos discursos políticos. Em geral, ampliaram-se aos brasileiros as possibilidades de acesso à informação, lazer e consumo. As condições de vida nas cidades diminuíram muitas das distâncias entre homens e mulheres; práticas sociais do namoro à intimidade familiar também sofreram modificações (PINSKY, 2015, p. 608).

Mesmo com as condições de crescimento urbano e industrial vividos pelo Brasil no pós-guerra, assim como a diminuição das "distâncias" da condição de vida entre homens e mulheres, Pinsky deixa claro em suas colocações subsequentes que os "papéis femininos e masculinos" continuaram com distinções nítidas. Permanecia intrínseca à sociedade uma moral sexual diferenciada e mesmo com a mulher se inserindo cada vez mais no mercado de trabalho continuava cercada de preconceitos. A figura de "chefe da casa" era essencialmente masculina. A casa e a rua delimitavam as representações sobre os papéis destinados às mulheres e aos homens (DEL PRIORE, 2013.). Além disso, o fim da guerra trouxe consigo campanhas estrangeiras pregando que o esforço de guerra das mulheres ${ }^{4}$, à época dos

\footnotetext{
${ }^{3}$ Um exemplo pode ser visto na própria produção literária da época, na qual, as representações do feminino tomavam caminhos para além do recato. No ano de 1954, em Ciranda de Pedra, Lygia Fagundes Telles lançava sob uma atmosfera feminina (com autora e personagens femininas) assuntos ligados à traição da mulher, violência doméstica, loucura e alteridade feminina. Cf. TELLES, 2009.

${ }^{4}$ Durante as duas Grandes Guerras (1914-1918 e 1939-1945) muitas mulheres tiveram ao seu encargo funções ditas produtivas, como: os trabalhos no campo, nos setores industriais, como médica e enfermeiras, e até mesmo,
} 
combates, fosse substituído pela volta ao lar, à mulher como rainha da casa, a volta aos valores tradicionais da sociedade, inerentes ao estilo de vida do século XIX:

\begin{abstract}
Na família-modelo dessa época, os homens tinham autoridade e poder sobre as mulheres e eram os responsáveis pelo sustento da esposa e dos filhos. A mulher ideal era definida a partir dos papéis femininos tradicionais ocupações domésticas e o cuidado dos filhos e do marido - e das características próprias da feminilidade, como instinto interno, pureza, resignação e doçura. Na prática, a moralidade favorecia as experiências sexuais masculinas enquanto procurava restringir a sexualidade feminina aos parâmetros do casamento convencional (PINSKY, 2015, p. 608-609).
\end{abstract}

É neste contexto de redefinição dos papéis tradicionais, de afirmação da feminilidade pelo comportamento doméstico, puro, doce e resignado que se destaca a expansão das revistas femininas ${ }^{5}$. Tratando de "assuntos femininos", os periódicos continham variadas regras de comportamento, opiniões sobre casamento, sexualidade, trabalho feminino e felicidade doméstica. Os exemplares de O Cruzeiro, Jornal das Moças e Querida estavam embutidos de padrões femininos e masculinos - com papéis bem definidos - e uma noção bem delimitada de família modelo, que segundo Pinsky seria: branca, de classe média, nuclear e hierárquica (PINSKY, 2015, p. 607-639).

As revistas dos anos 1950 influenciavam a vida das mulheres de classe média não deixando, porém, de serem influenciadas pelas mudanças sociais vividas e promovidas por essas mulheres. A realidade da inserção feminina nos ramos trabalhistas, fora do lar, exemplifica as abordagens do assunto nesses veículos midiáticos. Entretanto, o modelo preconizado pelas revistas apontava para a relação restrita e necessária da mulher com o casamento, com a maternidade e com os afazeres do lar - uma espécie de destino natural e inexorável.

Já os anos 1960 tiveram real importância para transformações dos papéis femininos. Com interesse especial nos levantes feministas, tomamos como primordiais as querelas

em alguns cenários, no fronte dos conflitos. Por se tratarem de espaços socialmente masculinizados, ao fim dos combates, houve a tentativa (principalmente por meio de propagandas - fortemente amparadas na mídia estadunidense com a "mulher, rainha do lar") de remodelar o papel feminino, ou seja, recolocá-la em seu "lugar natural", o âmbito privado, a casa.

${ }^{5}$ As "fontes impressas" nos permitem trazer concepções históricas acerca de seu papel que, atingindo determinados públicos, podem ser problematizadas e identificadas como produto imediato entre a vivência de determinado acontecimento e sua narração. Tânia Regina de Luca acredita que os discursos adquirem significados de muitas formas, e que a ênfase em determinados temas, a linguagem utilizada e a natureza do conteúdo estão diretamente associadas ao público que o jornal ou a revista pretendem atingir. Ressalta que os conteúdos presentes nos periódicos não podem ser desvinculados do lugar ocupado pela publicação na história da imprensa, de seu lugar de produção, dos fatos políticos ligados aos processos sociais. Esse movimento faz parte da interação entre indústria cultural e sociedade, onde o lugar de "retorno" do político revive ou renova-se pelo fato de utilizar-se de contribuições teórico-metodológicas alcançadas nas últimas décadas no âmbito da História Cultural. Cf. LUCA, 2008. 
levantadas ou trazidas por gerações de mulheres que, vivendo nas complexas décadas de 1960 a 1980, sobressaíram-se em prol das garantias, aumento e fomento de seus direitos.

Apesar da fase de opressão, as interferências estrangeiras ecoaram e fizeram com que começasse a ser repercutido no Brasil o movimento feminista que estava sendo organizado na Europa e nos Estados Unidos. Foram publicados os primeiros livros de feministas brasileiras e "os jornais, as revistas, o cinema, o teatro e a televisão começaram a dar espaço para uma nova mulher preparando o terreno para a década seguinte quando surgiram, em todo o Brasil, os movimentos organizados de mulheres" (GOLDENBERG, 1994, p. 446) ${ }^{6}$. O trabalho fora de casa crescia e a mulher começou a desempenhar profissões "essencialmente masculinas". Isso tudo modificou razoavelmente o papel feminino no âmbito público e privado. É justamente no rumo extra-doméstico feminino que Paola Cappellin Giulani atenta-se em seu trabalho sobre os movimentos de trabalhadoras e a sociedade brasileira (GIULANI, 2015, p. 640-668.). Referindo-se à "crise da divisão sexual no trabalho e na representação sindical" pós anos 1960, Giulani ressalta que:

Nesse percurso, às vezes tortuoso, aparecem com maior clareza os limites daquilo que seria próprio das mulheres, daquilo que lhes seria reconhecido, permitido ou atribuído como característico de sua "natureza social". Por comparação, pode-se também compreender o que seria próprio da "natureza social do homem". Mais ainda! Chega-se à consciência de que qualquer definição dos papéis, da imagem, da identidade e dos códigos de comportamento da mulher, é instável e transitória, já que tais concepções culturais são o resultado do confronto entre os valores dominantes e os anseios de mudança (GIULANI, 2015, p. 649).

Mesmo se tratando de um contexto submerso por uma tradição que delimitava os "papéis sociais", os anos 1960 configuram-se também como procedente de mudanças nas definições destes papéis nos mais variados setores da vida, neste caso, com destaque para o trabalhista. Não é de se admirar, portanto, que nos anos subsequentes víssemos despontar variados grupos sociais produzindo contestações políticas, econômicas, ambientais e de gênero. Com a ascensão dos governos militares ${ }^{7}$, insurgiram também questionamentos de organizações sindicais. Além disso, tivemos no movimento das mulheres rurais e na participação das mulheres dos centros urbanos a ruptura de um ideal que, para além do lar, desbrava as ruas, o cenário social e político do país. Dentre os movimentos sociais ocorridos entre 1960 e 1970, ressaltamos: os Movimentos Estudantis da UNE (União Nacional dos

\footnotetext{
${ }^{6}$ Grifo da autora.

${ }^{7}$ Em 1964, o golpe militar derrubava um presidente (João Goulart) e instituía a ditadura no Brasil. Para Ferreira \& Gomes, o movimento ocorrido em $1^{\circ}$ de abril de 1964 , foi um golpe civil e militar, que acabava com a experiência democrática iniciada no final de 1945. Cf. FERREIRA; GOMES, 2014.
} 
Estudantes, 1968) ${ }^{8}$; Movimento de Lutas por Creches (1970) ${ }^{9}$; o Movimento Brasileiro pela Anistia $(1974)^{10}$; e a criação dos Grupos Feministas e dos Centros de Mulheres (1975) ${ }^{11}$.

Ao trabalharem os impactos do golpe que derrubou o presidente João Goulart em 1964, Ferreira e Gomes discutem os fatores que puseram fim ao regime democrático e instituíram a ditadura no Brasil. Nesse contexto, os autores evidenciam a participação de mulheres em marchas de delegações femininas em municípios do interior paulista, onde a mulher se fazia representar pela figura das primeiras-damas (FERREIRA; GOMES, 2014, p. 304). A participação de mulheres, também ocorria por intermédio de mães de classe média, ligadas à vertente católica, com a Marcha da Família com Deus pela Liberdade.

\begin{abstract}
Segundo cálculos divulgados na imprensa, no mínimo, participaram da Marcha cerca de quinhentas mil pessoas. Mas, considerando os que, parados, assistiram à passeata nas ruas de acesso, é possível calcular umas oitocentas mil pessoas. Isso é muita gente; em 1964, muita gente mesmo. Segundo a historiadora Aline Presot, estiveram presentes à Marcha delegações femininas de trezentos municípios do interior paulista. A mulher brasileira se fazia representar igualmente pelas primeiras-damas - as esposas de governadores - de estados importantes, como São Paulo, Guanabara, Rio Grande do Sul, Paraná e Bahia. Esse foi um sinal verde evidente da perda de apoio que presidente sofreu após o comício (FERREIRA; GOMES, 2014, p. 303-304).
\end{abstract}

Em contrapartida, nomes como o de dona Neusa Brizola (esposa de Leonel Brizola), convocavam reuniões conjuntas da Liga Feminina da Guanabara e do Movimento Nacionalista Feminino, planejando um outro tipo de manifestação:

\footnotetext{
8“Ao longo de toda década de 1960 o movimento estudantil ganhou força no Brasil, e esse impulso culminou no $30^{\circ}$ Congresso Nacional da UNE, realizado em outubro de 1968 no município de Ibiúna”. “....estudantes e artistas engrossaram a passeata dos Cem Mil no Rio de Janeiro, pedindo democracia, liberdade e justiça. Disponível em: http://www.une.org.br/noticias/estilhacos-de-memoria-sobrevida-e-dissolucao-da-une-1969-1973/. Acesso em: 19 ago. 2017.

${ }^{9}$ Com a incorporação crescente das mulheres ao mercado de trabalho, a partir da década de 1970, houve a proliferação de creches comunitárias no Brasil. Assim como, ampliou-se a demanda por espaços de educação e cuidados dos filhos dessas mulheres, logo reivindicações junto ao poder público emergiram. Cf. TAVARES, Maria Tereza Goudard. Movimentos sociais e a formação política de mulheres na luta por creches: a experiência do "Artcreche" em São Gonçalo. Zero-a-Seis, v. 19, n. 36, 2017, UFSC. p. 272-289. Disponível em: https://periodicos.ufsc.br/index.php/zeroseis/article/view/1980-4512.2017v19n36p272/35619. Acesso em: 19 ago. 2017.

10“'Fruto de uma frente política e social que mobilizou o conjunto dos movimentos sociais e dos setores da oposição. Por seu caráter humanitário e político, sensibilizou amplamente a população e teve repercussão internacional. Mesmo sem ter alcançado totalmente seus objetivos, a votação da Lei da Anistia, em agosto de 1979, representou uma grande vitória das forças democráticas sobre o regime". Cf.: http://memorialdademocracia.com.br/card/anistia. Acesso em: 19 ago. 2017.

11،'Movimento surgido no Brasil em 1975, na ocasião da Instituição pela Organização das Nações Unidas (ONU) no Ano Internacional da Mulher, com os seguintes objetivos: identificar e denunciar as discriminações e as desigualdades que afetavam a situação da mulher brasileira, luta pela libertação das mulheres enquanto sexo dominado e oprimido, promover a conquista de direitos civis e de espaços públicos de atuação para as representantes dessa memória política." Cf.: http://www.fgv.br/cpdoc/acervo/dicionarios/verbetetematico/movimento-feminista. Acesso em: 19 ago. 2017.
} 
Foram poucas organizações de esquerda que se preocuparam com as Marchas da Família com Deus pela Liberdade. Dona Neusa Brizola, esposa de um líder de esquerda - mas mulher e mãe de "classe média" -, esteve entre os que avaliaram os fatos de forma diferente. Ela convocou uma reunião conjunta com a Liga Feminina da Guanabara e do Movimento Nacionalista Feminino para planejar um outro tipo de manifestação de mulheres para responder às Marchas. $\mathrm{O}$ seu projeto, porém, não foi levado adiante (FERREIRA; GOMES, 2014, p. 305).

Estudantes secundaristas, universitárias, trabalhadoras urbanas e rurais, promoviam suas organizações e lideranças surgiam. A mulher se fazia constantemente presente no âmbito político, embora tenha-se conferido certa marginalidade a esse tipo de participação. Em uma de suas pesquisas, a antropóloga Mirian Goldenberg buscou acompanhar do período de 1940 a 1970 as transformações ocorridas no campo político brasileiro (GOLDENBERG, 1996). Através de partidos e organizações esquerdistas e a partir da trajetória de algumas mulheres, a estudiosa realizou entrevistas com militantes, analisou biografias, autobiografias, artigos e entrevistas encontradas em jornais e revistas. A partir disso, Goldenberg gerou uma discussão sobre a construção social da identidade de gênero no interior desses partidos e organizações de esquerda do Brasil. Acreditando que a identidade surge entre semelhanças e diferenças entre as mulheres militantes e as mulheres "comuns", assim como entre as mulheres militantes e os homens militantes, a antropóloga percebeu um jogo bastante complexo. As militantes, no mais das vezes, comparadas aos homens tornavam-se "invisíveis", com posições secundárias dentro das organizações e partidos. Já comparadas às mulheres "comuns", as militantes eram vistas como mais corajosas, tendo maior capacidade de renúncia, sacrifício, mas sem a possibilidade de realizar o desejo de ter uma "vida normal": como esposa e mãe. No mais, Goldenberg colige que:

Anônimas, silenciosas, invisíveis... essas são as mulheres militantes que tentam recuperar o seu nome e a própria identidade contando a sua versão da história. Separadas dos companheiros, dos filhos, da família, vivendo uma vida clandestina, sofrendo violências físicas e psicológicas, essas mulheres adquiriram visibilidade nas últimas décadas. Suas histórias começam a ser contadas e a importância de suas presenças na luta política brasileira está sendo cada vez mais reconhecida, através da realização de pesquisas, documentários, filmes e publicação de biografias (GOLDENBERG, 1996, p. 17).

Uma luz sobre aspectos de um passado não tão distante, que evoca princípios identitários e/ou igualitários, mas que em decorrência de uma funcionalidade machista ficaram à margem da história. Fato que a cada dia vem se modificado através de pesquisas como a de Goldenberg, que buscam salientar os fazeres femininos: suas lutas, conquistas e aspirações. Os ideais de estética, aparência e beleza de tais períodos estão embutidos nesses 
fazeres e quereres, e a antropóloga citada obviamente não deixa de discuti-los. Levando em consideração as mudanças desencadeadas com o início do século $\mathrm{XX}$, vemos uma série de acontecimentos que culminaram numa época norteada por revoluções de cunho político (como o desenvolvimento do socialismo iniciado na Rússia em 1917), econômico (através da ferrenha batalha entre dois modelos: capitalismo x socialismo/comunismo) e social (com lutas dos mais variados seguimentos, como a causa ambiental, as questões de classe e gênero). Compreendendo que todos estes vieses desembocam nas questões culturais, assimilamos que as representatividades de tais acontecimentos na vida dos indivíduos estão extremamente interligadas. É nesse sentido que Goldenberg, posteriormente, trabalha a aparência feminina como produto do culturalmente desenvolvido, que ora fabrica, ora é criado para fornecer normas e ideias acerca da imagem:

Na segunda metade do século XX o culto ao corpo ganhou uma dimensão social inédita: entrou na era das massas. Industrialização e mercantilização, difusão generalizada das normas e imagens, profissionalização do ideal estético com a abertura de novas carreiras, inflação dos cuidados com o rosto e com o corpo: a combinação de todos esses fenômenos funda a ideia de um novo movimento da história da beleza feminina e, em menor grau, masculino (GOLDENBERG, 2002, p. 08).

O papel sem precedentes das funções adquiridas pelo corpo e pela imagem, os cuidados com a imagem, com a própria imagem, passam a reverberar a massificação de modelos estéticos, no qual a beleza feminina ganhou destaque fundamental. As relações estabelecidas pela tríade beleza-saúde-juventude passaram a ser fundamentais (GOLDENBERG, 2002, p. 8). As revistas femininas, assim como o cinema e a televisão recém-chegada no Brasil nos anos 1950, adquiriram espaço num meio onde enquadrar-se num determinado modelo de comportamento e aparência tornava-se primordial para ser "bem quisto" na sociedade. Vale lembrar que, a cada período, novas propostas e paradigmas surgiam e surgem. Amplificando o conceito de 'beleza' devemos atentar-nos para seus valores dicotômicos a cada momento histórico, pois em meio aos múltiplos acontecimentos de uma dada sociedade, mecanismos que reverberam as representações daquilo que é praticado socialmente estão presentes. É nesse sentido que o papel da mídia se fez e se faz relevante indo a favor ou na contramão das configurações estabelecidas. Em relação ao movimento feminista, que ganhava novas proporções nesse período, não foi diferente. 


\section{Os modos da moda}

"Os conteúdos [das revistas] eram simples: sugestões para a gestão da casa e conselhos práticos de estilo e de beleza" (COLELLA, 2015, p. 20). Com a chegada dos anos 1960 e 1970 as mudanças ocorreriam de maneira ainda mais enérgica. A mulher ia deixando de ser valorizada apenas por sua relação com o lar e a família, dando também prioridade à carreira profissional. Os anos marcados pelas revoluções sociais e os movimentos de emancipação feminina conduziam a novas identidades femininas. As mutações na dinâmica social interferiam nas publicações que sem deixarem de oferecer às leitoras conselhos sobre bem-estar, lazer e feminilidade, passavam a privilegiar temas relacionados à carreira, começando a abordar questões de gênero, conferindo novos olhares ao corpo e à sexualidade. A própria visão a respeito dos periódicos femininos seguia sendo alterada:

Em meados dos anos 70, as feministas consideravam as revistas com conteúdos femininos um exemplo de opressão das mulheres. A publicidade mais não fazia do que assinalar os defeitos das leitoras, convencendo-as de que o uso de determinados produtos podia mudar o seu aspeto e as suas expectativas de vida, garantindo a saída do mundo da insatisfação e o aumento da sua autoestima. A sociedade não tinha interesse em incentivar as novas necessidades das mulheres; bastava manter os parâmetros já definidos da feminilidade (COLELLA, 2015, p. 28).

Foram, justamente, grupos ativistas das décadas de 1960 e 1970, principalmente na Europa e nos Estados Unidos, que ligaram a ideia "feminilidade" à noção de "estereótipo" e ambos a uma conotação negativa. Isso ocorreu não somente em relação às mulheres, mas também aos negros, latinos, americanos, gays e lésbicas (SILVEIRINHA, 2004). A mídia encontrava-se em meio às críticas conexas a um juízo de subordinação que ao distorcer suas leituras da sociedade e de seus elementos, denegria, por sua vez, as marcas identitárias existentes. A relação da mulher com sua aparência e comportamento estaria sendo, segundo essa perspectiva, regida de maneira incongruente com o real. $\mathrm{O}$ fato, por exemplo, das revistas femininas e a publicidade exaltarem o "uso de produtos cosméticos para todas as mulheres" seria condizente com uma espécie de "massificação" do ser mulher (LIPOVETSKY, 2009, p. 119).

Assim, a relevância do contexto histórico-social e suas interferências no comportamento, na aparência da mulher e no "ser feminino", convertiam-se em práticas e representações culturais, nas quais a influência midiática auxiliava numa via de mão dupla: ora o rumo visava à apropriação de ideias, conceitos, padrões comportamentais e estéticos; ora tinha-se como meta a "desapropriação" daquilo que é imposto, dado como certo, belo ou 
preferível, incorporando novos ideais ou resgatando antigos modelos daquilo que "melhor" expressaria a vivência da mulher. Trata-se de um caminho não linear com rupturas e permanências. Algumas rupturas, entretanto, sempre serão passíveis de questionamento quando em vez de destoar-se de um viés opressor, como o engajamento nas lutas por igualdade de direitos entre os gêneros, acabam criando outro.

Uma problematização nesse sentido, em relação à época estudada, encontramos na obra Histórias e Conversas de Mulher, de Mary Del Priore, onde a autora descreve que as “carnudas estrelas dos anos 1950”, são substituídas por figuras "esquálidas” nos anos 1960 (DEL PRIORE, 2013). Segundo Del Priore, um quadro que se estabelece como estigmatizador da gordura, lipofóbico, no qual o padrão de estética burguês do século XIX, que associava riqueza à gordura é deixado para trás. A identidade social, no que diz respeito aos ideais de beleza, ganha novo tônus. Encaixar-se no “modelo da vez" é, para Del Priore, uma maneira de continuar-se oprimindo, não mais pela imposição de uma sociedade sexista de papéis extremamente definidos entre homens e mulheres, mas através das próprias mulheres, que passam a cobrar de si mesmas alcançar tal padrão, por vezes, surreal.

Ademais, essa visão "opressiva” que seria instaurada pelas próprias mulheres em prol do "estarem na moda" necessita de certos cuidados. Do contrário, cometeríamos novamente o erro de vermos as mulheres como objetos submissos à estrutura ao redor, em vez de indivíduos receptores e reformuladores daquilo que é produzido pela cultura e pela mídia, como agentes condutoras de um processo. A beleza entendida como organismo intrínseco a esse sistema, portanto, mais que imposição, torna-se parte fundamental da vivência feminina. Algo que transmuta nos mais variados setores (ao interligar mídia, comércio e sociedade), conduzindo, inclusive a um sentimento de pertencimento, em que a (des)apropriação de modismos se configura como dado de sua própria representação. As transformações ocorridas nas questões comportamentais e nas noções de beleza em determinada época são, dessa maneira, produto da conversação entre os indivíduos, suas práticas e seu meio.

Ao analisarmos as questões que envolveram as representações do feminino trabalhados pela mídia impressa durante as décadas de 1950 a 1970, deparamo-nos com uma postura específica, de propósitos bem definidos que implicaram em concepções de lugares de atuação social das mulheres. 


\section{As modas nas mudanças}

Sendo a indumentária fator relevante nos processos de rupturas em cada época, Selma Garrini faz um apanhado daquilo que de 1950 a 1970 era o "padrão de beleza", ou seja, o "ideal" a ser conquistado e que foram com o passar dos anos construindo-se, modificando-se, reinterpretando-se:

Na década de 1950, Marilyn Monroe foi a marca da sexualidade feminina e do corpo, símbolo de desejo e de consumo. As formas mignons, de atrizes como Audery Hepburn, se avolumaram, mas as cinturas de pilão se mantiveram intactas. Nos anos 1960, John e Jaqueline Kennedy, com seus corpos magros e sem exageros simbolizaram a elegância e o poder. Na moda, a modelo inglesa Lesley Hornby, também conhecida como Twiggy, que em inglês significa galho seco, representa um novo padrão de beleza, extremamente jovem e magra. No Brasil, o corpo violão dá lugar a um corpo tábua. Nos anos de 1970, o corpo excessivamente magro das modelos ditava a moda feminina e passa a ser objeto de apreciação e de desejo. No Brasil, os corpos são mais politizados, buscando expressar mais a liberdade do que propriamente a beleza saudável de quem vive em contato com a natureza. Em 1971, aparece Leila Diniz, como símbolo de liberdade e de espontaneidade. Ao exibir sua barriga de grávida, de biquíni, na praia de Ipanema, escandalizou e lançou moda (GARRINI, 2007, p. 3).

Nesse panorama, a "importação" de ícones de beleza é algo discutido por Garrini, bem como a objetificação do corpo e os princípios da saúde, em prol da beleza, mas também daquilo que cada período "pedia". Os corpos "politizados" dos anos 1970, eram conduzidos pela magreza e pela aspiração de liberdade. A cultura hippie conclamava esses preceitos e passava a estabelecer-se não somente como um estilo, uma filosofia de vida, mas também como a criação de um estilo modista. Nas palavras de Renata Cidreira percebemos a questão da aparência feminina vinculada à moda pop e hippie configurando-se, contudo, como meio de aproximação de uma condição de igualdade entre homens e mulheres nos finais de 1960 (CIDREIRA, 2008). A releitura e implementação de peças "tipicamente masculinas" como as calças, ao guarda-roupas feminino, vem no sentido de uniformizar questões que antes desassociavam. O termo unissex tornava-se constante, inclusive na publicidade. As ousadias modistas insurgiam através de iniciativas como as da estilista britânica Mary Quant, que ao criar as minissaias sugeria a permissão do movimento, colocando as cinturas para baixo, usando faixas horizontais e inserindo modelos triangulares de pregas na linha da bainha. As roupas ganhavam ares divertidos, eram fáceis de usar, rejeitando tudo que fosse formal, "engomado". Os jovens, enquanto consumidores, passavam a associar e a buscar na moda aspectos de dinamismo e modernidade, não somente por meio das mulheres, pois o público masculino também se reformulava: 
De fato, até os anos 60, havia uma maneira de vestir-se, com a qual homens e mulheres, seguindo-a à risca, mantinham acentuadas as diferenças de sexo. Até aquela década, também estava na roupa a diferença de algumas posições sociais. Particularmente o terno indicava situações de trabalho, status político e social, mas sobretudo uma condição masculina urbana. Com o aparecimento e expansão da moda hippie tudo começou a mudar: primeiro a redução das diferenças no vestuário de homens e mulheres; depois a adoção de todo um estilo informal de portar-se e vestir-se, com a perda da posição central do terno, sem mencionar a mudança nos cortes de cabelos masculinos, antes curtos, passando a cair sobre os ombros, em desalinho, entre outras alterações (CIDREIRA, 2008, p. 40).

Para Cidreira ao compreendermos a moda como um fenômeno próprio da sociedade de consumo que está inserida na cultura de massas, na cultura do pop, conseguimos adquirir uma nova dimensão a partir do momento em que ela começa a fazer parte do meio quanto manifestação artística e cultural. As condensações realizadas nos vestuários femininos e masculinos com calças para elas e cabelos compridos para eles, por exemplo, eram maneiras de criar ou recriar aquilo que passava a representar os indivíduos na época. Desse modo, a força da aparência volvia-se como fator de empoderamento, constituindo e solidificando determinados grupos através da indumentária. A vestimenta tornava-se, nos anos 1970, um dos mais significativos emblemas das transformações que os jovens desejavam. A moda, adquiria uma conotação que ia além do elemento visual, passando a ser "um artifício que se cola ao corpo, a própria pele, como uma verdadeira extensão do ser humano" (CIDREIRA, 2008, p. 41).

Podemos inferir, no mais, que a moda se fazia presente, e até mesmo necessária, a partir do momento em que deixava de ser algo funcional, como adereço que cobre o corpo ou fator de identificação de sexos. A moda passava a representar um status, que detendo certa estética criava formas de comunicações não-verbais. Conseguia-se transmitir informações aos receptores por meio da imagem que se criava ou que se aderia, incorporava. Vista ainda como aceitação cultural e social, a moda proporcionava novas ondas de cores e de formas onde as roupas fundamentam-se no eu coletivo, por vezes, inconsciente em seu processo construtor ou reformulado. A escolha em si do vestuário já propiciava um meio para analisar como os indivíduos interpretavam e reinterpretavam a cultura para seu próprio uso. É justamente isso que ocorre nas décadas de 1950 a 1970. Um ambiente no qual a difusão do discurso midiático reverberava uma organização dos modos e das modas na esfera imagética e textual. Lançando modos de comportar-se socialmente ou reverberando a quebra de paradigmas dentro da sociedade, os periódicos comportavam em cada época um "perfil”" de mulher e, dentro de um mesmo período, as dicotomias existentes entre eles. 
Pois, na realidade, as variadas abordagens conferidas aos setores da vivência feminina são fruto da existência de diferentes "tipos" de mulheres, suas mudanças, suas continuidades e o papel da sociedade, de forma mais ampla, em conduzir, enxergar e até mesmo coibir esses processos. É nesse sentido que entendemos, de fato, o quão relevante são os movimentos, também, de continuidade, para entendermos o momento vivido no Brasil. Um novo governo, novos direcionamentos políticos, novos movimentos envolvendo a questão de gênero e participação social, fatores essenciais para compreendermos os dilemas, aspirações e coibições circunscritas no cotidiano das mulheres daquele tempo.

\section{Referências bibliográficas}

BARBOSA, Marinalva Vieira. Sobre a problemática de pôr as emoções como objeto de discurso. Estudos da Língua (gem), v. 5, n. 2, 2007. Disponível em: http://www.cpelin.org/estudosdalinguagem/ojs/index.php/estudosdalinguagem/article/viewFil e/79/198. Acesso em: 07 jul. 2017.

BASSANEZI, Carla. Revistas femininas e o ideal de felicidade conjugal (1945-1964). Cadernos Pagu, n. 1, a 07. p. 111-148. 1997.

CIDREIRA, Renata Pitombo. A moda nos anos 60/70 (comportamento, aparência e estilo). Revista do Centro de Artes, Humanidades e Letras. Salvador, v. 2, n. 1, 2008. Disponível em: http://www2.ufrb.edu.br/reconcavos/edicoes/n02/pdf/Renata.pdf. Acesso em: 07 jul. 2017.

COLELLA, Roberta. A Imagem da Mulher nas Revistas de Moda: o caso da Vogue. Relatório de Estágio em Comunicação e Jornalismo. Coimbra: Universidade de Coimbra, 2015. Disponível em: https://estudogeral.sib.uc.pt/bitstream/10316/29877/1/tesicompletaRobertaColella.pdf. Acesso em: 20 jan. 2017.

DEL PRIORE, Mary. Histórias e conversas de mulher. São Paulo: Planeta, 2013.

FERREIRA, Jorge Luiz; GOMES, Angela Maria de Castro. 1964: o golpe que derrubou um presidente, pôs fim ao regime democrático e instituiu a ditadura no Brasil. Rio de Janeiro: Civilização Brasileira, 2014.

GARRINI, Selma Peleias Felerico. Do corpo desmedido ao corpo ultramedido: reflexões sobre o corpo feminino e suas significações na mídia impressa. In.: Congresso Nacional de História da Mídia. 2007. Disponível em: http://www.intercom.org.br/papers/outros/hmidia2007/resumos/R0037-1.pdf. Acesso em: 07 jul. 2017.

GIULANI, Paola C. Os Movimentos de Trabalhadoras e a Sociedade Brasileira. In.: DEL PRIORE, Histórias das Mulheres no Brasil. 10 ed. São Paulo: Contexto, 2015.

GOLDENBERG, Mirian. Leila Diniz: A Arte de Ser Sem Esconder o Ser. Revista Estudos Feministas. Rio de Janeiro: CIEC/Escola de Comunicação UFRJ, v. 2, n. 2, 1994.

GOLDENBERG, Mirian. Mulheres e militância política de esquerda no Brasil: uma história não contada. XX Encontro Anual da ANPOCS. Caxambu, 1996. Disponível em: http://www.anpocs.com/index.php/encontros/papers/20-encontro-anual-da-anpocs/gt-19/gt114/5395-mgoldenberg-mulheres/file. Acesso em: 20 jan. 2017.

GOLDENBERG, Mirian. Nu e Vestido. Dez antropólogos revelam a cultura do corpo carioca. Rio de Janeiro: Record, 2002. 
LIPOVETSKY, Gilles. O império do efêmero: a moda e seu destino nas sociedades modernas. São Paulo: Companhia das Letras, 2009.

MIGUEL, Raquel de Barros Pinto. Corpos femininos e publicidade na revista Capricho (décadas de 1950-1960). In.: Seminário Internacional Fazendo Gênero 8, 2008, Florianópolis. Anais do Seminário Internacional Fazendo Gênero 8, 2008. Disponível em:http://www.fazendogenero.ufsc.br/9/resources/anais/1278297022_ARQUIVO_textocompl eto-Faz.Gen.9.pdf. Acesso em: 20 jan. 2017.

PINSKY, Carla Bassanezi. Mulheres dos Anos Dourados. In.: DEL PRIORE, Mary. História das mulheres no Brasil. 10a ed. São Paulo: Contexto, 2015.

SILVEIRINHA, Maria João. Os media e as mulheres: horizontes de representação, de construção e de práticas significantes. As Mulheres e os Media. Lisboa: Livros Horizonte, 2004.

TAVARES, Maria Tereza Goudard. Movimentos sociais e a formação política de mulheres na luta por creches: a experiência do "Artcreche" em São Gonçalo. Zero-a-Seis, v. 19, n. 36, 2017, UFSC. p. 272-289. Disponível em: https://periodicos.ufsc.br/index.php/zeroseis/article/view/1980-4512.2017v19n36p272/35619. Acesso em: 19 ago. 2017. 